\title{
Research on the Problems and Countermeasures of the Cultivation of Adult College Students' Innovation and Entrepreneurship Ability in the Internet Era
}

\author{
Qiangqiang Zhou \\ Zhejiang Open University, Hangzhou, China \\ Email: 1037782896@qq.com
}

How to cite this paper: Zhou, Q.Q. (2021) Research on the Problems and Countermeasures of the Cultivation of Adult College Students' Innovation and Entrepreneurship Ability in the Internet Era. Open Access Library Journal, 8: e7718.

https://doi.org/10.4236/oalib.1107718

Received: July 1, 2021

Accepted: July 24, 2021

Published: July 27, 2021

Copyright $\odot 2021$ by author(s) and Open Access Library Inc.

This work is licensed under the Creative Commons Attribution International License (CC BY 4.0).

http://creativecommons.org/licenses/by/4.0/

\section{(c) (i) Open Access}

\begin{abstract}
In the Internet era, the cultivation of innovation and entrepreneurship ability of adult college students has always been the focus of adult education in China. The rapid development of China's economy and the rapid popularization of Internet technology provide an unprecedented opportunity and stage for the cultivation of innovation and entrepreneurship ability of adult college students and open a new engine for the cultivation of innovation and entrepreneurship ability of adult education in China. Through consulting the relevant literature and practical exploration, this paper finds that there are many problems in the cultivation of adult college students' innovation and entrepreneurship ability in the Internet era, such as lack of talents, low entrepreneurship rate and success rate, imperfect school-enterprise cooperation system and mechanism, and unbalanced willingness of both sides, which are related to the low effectiveness of adult college entrepreneurship education, poor financing channels for college students' entrepreneurship, unperfect school-enterprise cooperation system and mechanism, weak entrepreneurial environment and other factors are closely related. In view of the above problems, this paper puts forward countermeasures from four aspects, in order to provide useful reference for the cultivation of adult college students' innovation and entrepreneurship ability in the Internet era.
\end{abstract}

\section{Subject Areas}

Higher Education

\section{Keywords}

Internet Age, Adult Colleges and Universities, Innovation and Entrepreneurship, Problem Countermeasure Research 


\section{Introduction}

The education of adult college students in the Internet era is oriented to adults, with the main goal of cultivating adult's innovative and entrepreneurial consciousness and ability. Developing innovative and entrepreneurial adult education is an important way to cultivate a large number of talents with innovative and entrepreneurial consciousness and ability. According to the current economic and social development needs of China, encouraging and guiding adult college students to cultivate innovative talents has important strategic significance for developing high-quality entrepreneurial resources, promoting supply-side reform and industrial structure transformation, and realizing sustainable economic and social development. Therefore, it can be seen that the research on the problems and countermeasures of strengthening the cultivation of innovation and entrepreneurship ability of adult college students in the Internet era has become a subject that needs to be paid attention to at present and in the future.

\section{Current Situation of Cultivation of Innovation and Entrepreneurship Ability of Adult Higher Education in the Internet Era}

\subsection{The Education of Innovation and Entrepreneurship Ability Started Late in China}

The cultivation of students' innovative and entrepreneurial thinking in foreign adult colleges is ahead of China. Among the twelve standards of undergraduate training in Princeton University, the quality structure of innovative and entrepreneurial talents established is one of the important indicators. According to statistics, nearly $40 \%$ of American universities offer entrepreneurship courses in undergraduate education, nearly $25 \%$ offer entrepreneurship courses in graduate education, and $40 \%$ offer entrepreneurship courses at both undergraduate and graduate levels. Among them, community colleges bear the heavy burden of adult education, accounting for more than half, which has eased the pressure of social employment. It adds new vitality to economic development [1]. And adult innovation of entrepreneurship education in China started late, low starting point, the adult education due to the flexibility of education, as well as for students admitted to three care (admission without examination, admission with bonus points and admission with reduced points), leading to the students' quality is uneven, the adult education development stumbled, failed to reach a unified model of intensive education and training. Therefore, the training mechanism of students' innovation and entrepreneurship ability should rely on the cooperation of various forces, and it is urgent for all forces to jointly think about countermeasures and strengthen the training of entrepreneurial thinking [2].

\subsection{The Scale of Internet Users Has Grown Rapidly}

The scope of adult education is not restricted by age and gender, and the students are adults with life experience and work experience. Experience not only 
increases students' cognitive ability but also expands students' options after graduation. Entrepreneurship has more advocates among adult education students. On July 4, 2015, signed and approved by Premier Li Keqiang, the State Council issued the Guiding Opinions on Actively Promoting the "Internet Plus" Action. The number of Internet users in China has increased from 457.3 million in 2010 to 668 million now, and the Internet penetration rate is as high as $48.8 \%$. Among them, nearly 19 million new rural Internet users have been added, and the number of Internet users with junior middle school education or below is also increasing [3]. On November 23, 2020, General Secretary Xi Jinping sent a congratulatory letter to the World Internet Conference and Internet Development Forum held in Wuzhen, Zhejiang Province, pointing out that in today's world, a new round of scientific and technological revolution and industrial transformation is in the air, driving the rapid development of digital technology. Since the outbreak of COVID-19, telemedicine, online education, sharing platforms and collaborative work have been widely used. The Internet has played an important role in promoting economic recovery, ensuring social functioning and promoting international cooperation in fighting the epidemic. These all say that our country has entered the Internet era in an all-around way, and the business opportunities contained on the Internet will also have more advantages compared with the traditional industries. According to Forbes China College Student Rich List, the number of college students who are engaged in Internet entrepreneurship is as high as $60 \%$. It is a historical necessity to conduct innovation and entrepreneurship on the Internet, so it is also an inevitable trend to cultivate the innovative and entrepreneurial thinking of adult education students [4].

\section{Difficulties Faced by Adult College Students in the Cultivation of Innovation and Entrepreneurship}

Through referring to relevant literature and practical exploration, we found that, under the joint efforts of all aspects, the cultivation quality of innovation and entrepreneurship ability of adult college students in China has been improved, but there are still some problems that need to be solved urgently.

\subsection{Insufficient Resource Input}

First, the lack of investment in teachers, some high academic qualifications, high professional titles of adult university teachers keen on research projects, to participate in adult university students education disdain; Two is insufficient energy input, in many adult colleges, whether it's decision-making, management, teaching and service layer, is the age of the Internet adult college students' innovative undertaking ability training as a subsidiary occupation, the second industry, not treat it as an independent and important, has its own law of development and special requirements of enterprise, make the adult education lost its appeal and vitality; The vitality of adult education lies in practical education, but many adult colleges and universities do not use the limited practical teaching resources and 
practice bases for classroom education, instead of developing the tertiary industry, resulting in the low level and quality of classroom education.

\subsection{Education Outcomes Are Not Commensurate with Their Status and Responsibilities}

The age of the Internet adult college existence value is still the internet mode of talent training, scientific research, social services, and training of talents should have "double gen" consciousness and ability. These talents should include thousands of adult workers, from this perspective. The adult college scientific research and social service has only converted to improve productivity to be meaningful. The most important carrier and improve productivity is to improve the comprehensive quality of adult laborers Internet mode and the "double gen" ability, it needs the "double gen" type of adult education, adult university contribution in this respect and social expectations have a larger gap, and status, responsibility, do not match, thinking mode is more conservative.

\subsection{There Is Insufficient Talent Reserve and Teaching Quality Needs to Be Improved}

Although the hardware and software facilities of adult colleges and universities in China have been greatly improved, on the whole, the talent pool of adult colleges and universities is still at a low level, and the overall lack of preparation for entrepreneurship education is an important reason for the low innovation and entrepreneurship ability. On the whole, the number of adult college students receiving systematic entrepreneurship education in China is not large. In August 2012, the Ministry of Education issued the "Basic Requirements for Entrepreneurship Education Teaching in Ordinary Undergraduate Schools (Trial)", which stipulates that "Fundamentals of Entrepreneurship" shall be incorporated into the teaching system of compulsory courses in colleges and universities, and the course shall be no less than 32 class hours and 2 credits [5]. However, due to a variety of reasons, the implementation is not ideal, and the entrepreneurial culture and entrepreneurial atmosphere in schools are in urgent need of promotion. This also directly leads to the adult college students' entrepreneurship success rate is not high. According to statistics, the national 97 earlier student enterprises, profit accounted for only $17 \%$. Only $30 \%$ of companies founded by students can survive in five years [6]. In addition to the reasons that the current entrepreneurial environment in China needs to be further improved and the financing channels of adult college students are too single, the lack of entrepreneurial experience and entrepreneurial ability of adult college students themselves is an important reason for the low success rate of entrepreneurship. Due to the lack of long-term cooperation mechanism between adult colleges and entrepreneurs, entrepreneurship education in colleges and universities generally focuses on knowledge over ability and classroom teaching over practical experience, which leads to the general lack of entrepreneurial practical skills among college students [7]. 


\subsection{The School-Enterprise Cooperation System and Mechanism Are Not Perfect, and the Willingness of Both Parties Is Not Balanced}

At present, the school-enterprise cooperation mechanism of adult colleges and universities in China is not perfect, which is mainly manifested in the following aspects: First, it is lack of interaction between adult colleges and enterprises. The complexity of entrepreneurship education and the marketability of entrepreneurship activities determine the strong willingness of colleges and universities to seek cooperation with enterprises. However, in view of the very low success rate of entrepreneurship among college students in China, the expected profit of entrepreneurship education cooperation between enterprises and universities is small, the effect is slow, and it is difficult to arouse the intrinsic interest of enterprises. Much school-enterprise cooperation is mainly promoted by external forces (such as the government and foundations), and there is a large space for active, complementary and reciprocal cooperation between universities and enterprises. Second, it is lack of long-term cooperation mechanism between adult colleges and enterprises. At present, the entrepreneurial cooperation between schools and enterprises is mostly short-term and informal, and the cooperation foundation is weak and susceptible to interpersonal relationship, personnel adjustment and other factors [8]. The cooperation between universities and enterprises in promoting the cultivation of innovation and entrepreneurship ability of college students is full of contingency and uncertainty, and there is a lack of long-term cooperation mechanism. Third, the cooperation mode between adult colleges and enterprises is unitary. At present, the cooperation between universities and enterprises is mostly carried out in the form of "entrepreneurial figures entering universities", and there are many forms of cooperation such as entrepreneurial figure interview, entrepreneurship salon and entrepreneurship forum. The single form of cooperation makes it difficult for college students to rely on enterprises. On the whole, the cooperation between universities and enterprises in the training of entrepreneurial talents, establishment of entrepreneurial funds, technological innovation and transformation, construction of practice bases, employment of entrepreneurial mentors, seat donation and other aspects is rarely seen.

\subsection{A Specialized Service Platform for College Students' Entrepreneurship Has Not Yet Been Established}

College students are special entrepreneurial groups full of entrepreneurial passion, full of adventurous spirit, with certain knowledge base but lack of experience. They need professional guidance from colleges and universities in market grasp and capital operation. On the whole, although many current policies include college students, they lack specialized services for the special entrepreneurial groups of college students. In addition, adult colleges also lack substantive measures in terms of entrepreneurial capital support for college students, 
and a specialized service platform for college students' entrepreneurship in adult colleges is urgently needed [9].

\section{Countermeasures and Suggestions for Cultivating the Innovation and Entrepreneurship Ability of Adult College Students in the Internet Age}

\subsection{Further Promote Entrepreneurship Education in Adult Colleges and Universities}

\subsubsection{Explore the Lifelong Entrepreneurship Education System}

The cultivation of innovation and entrepreneurship ability is a systematic project. Therefore, China's entrepreneurship education should focus on systematic construction and form a lifelong entrepreneurship education system that is interconnected and has its own characteristics. For example, the goals and requirements of entrepreneurship education at all levels and all kinds of schools should be designed as a whole. In the stage of basic education, the school curriculum should focus on the cultivation of entrepreneurship and entrepreneurship awareness. In vocational colleges, targeted entrepreneurial skills training should be strengthened according to the needs of different majors and industries. In colleges and universities, students' knowledge and entrepreneurial ability should be further enhanced according to their professional strengths.

\subsubsection{Build a Diversified Training System for Entrepreneurial Talents in Colleges and Universities}

In the construction of entrepreneurial society, entrepreneurship education in colleges and universities should be gradually advanced to be scientific, universal and professional. According to the requirements of scientific entrepreneurship education in colleges and universities, some adult colleges and universities should be encouraged to set up bachelor's, master's and doctor's degree systems according to their discipline and specialty advantages, so as to provide students with scientific entrepreneurship education. Popularization of entrepreneurship education requires universities to open university-wide general education courses, entrepreneurship intensive courses and professional integration entrepreneurship courses for all students, so as to provide universal entrepreneurship education for different types of students. The specialization of entrepreneurship education requires universities to open targeted and applied entrepreneurship courses according to the needs of social entrepreneurship talents training.

\subsubsection{Improve the Entrepreneurial Education System of Diversified Colleges and Universities}

In terms of organizational mode, entrepreneurship education resources of the whole school should be effectively integrated according to the characteristics of different types of colleges and universities. In terms of training methods, according to the needs of talent training, different combination of entrepreneurial practice bases for college students can be built to promote the integration of entrepreneurial education theory and practice. In terms of entrepreneurship teachers, 
it is necessary to train and build a team of full-time and part-time entrepreneurship teachers to provide high-quality entrepreneurship education.

\subsection{Enrich the Content of Innovation and Entrepreneurship Classes}

\subsubsection{Establish Exploratory Thinking Training Courses}

Carry out the construction of innovative modules of professional courses from the basic level, improve the construction of innovative courses of elective modules, and carry out the construction of comprehensive course modules of students' Internet thinking from the four dimensions of entrepreneurship, innovation, thinking and compound knowledge. Students with social experience are guaranteed to understand the basic historical background of the online model of big data and the socialization of world ethics, and the Internet thinking of truth seeking, openness, equality, collaboration and sharing is established in the course module. In the professional education, we should start from the depth of knowledge, pay attention to the construction of core ideas, establish innovative requirements from the two factors of content and teaching method, and pay attention to the interaction of subject frontier, social hot spot and cross-subject knowledge and professional knowledge. Establish the course platform of "innovation, creation and entrepreneurship", carry out integrated and unified planning and construction, and carry out demand-oriented simulation course construction and practical course implementation from the two modules of theory and practice. On the basis of professional courses, the establishment of matching elective courses, paying attention to the matching, coherence, design, innovation of the course; maintain the interaction and closeness between teachers and students in course learning.

\subsubsection{Promote the Cultivation of Innovative and Entrepreneurial Thinking}

The first classroom and the second classroom jointly promote the cultivation of innovative and entrepreneurial thinking, which is an integration process of the "four in one" teaching force of society, school, unit and student body. The task of the school is to establish a loose, free, allow failure, tolerance of mistakes of the school spirit and style of learning, with rich teaching content as the support, coordination of after-class resources and teaching system. In the first class, a large number of ideological and methodical courses should be opened to solve the problem of paying more attention to knowledge than methods at present and establish a training system of Internet innovation and entrepreneurship thinking in colleges and universities. Using "training needs analysis, teaching design, course content recommendation, students participate in selection and practical training implementation, training results, follow-up feedback effect" and so on seven big education process, the first class and second class, improve the consistency of training construction mechanism, theoretical knowledge content quickly into labor and productivity. Timely understand the industry structure adjustment 
and market demand changes, to adjust school specialized agencies, and with the Vancl, gather beauty is superior, electricity companies such as Alibaba in the courses, professional, teaching base, professional skills training, mentoring, etc in close cooperation, improve the Internet under the new formats creative entrepreneurial thinking training pertinence and effectiveness.

\subsection{University-Enterprise Alliance to Expand the Practice Base of Internet Entrepreneurship}

\subsubsection{Strengthen the Construction of Oriented Practice Bases}

The construction of oriented practice base requires adult colleges and universities to provide students with diversified selection and consultation services by strengthening the teaching staff and expanding the training scope on the basis of the original training system, and to incorporate the training content into the teaching plan and set up innovative credits, which are linked to the basic scores of students. At the same time, the practice of Internet innovation and entrepreneurship for adult education students is guided, and the experience of Internet innovation and entrepreneurship for adult education students is strengthened. The so-called practice base refers to the carrier with radiation function built around the Internet innovation and entrepreneurship practice of adult education students. It is not only a bridge connecting theory and practice, but also a medium connecting students and the Internet. There are two kinds of Internet innovation and entrepreneurship practice bases: off-campus and on-campus. In the construction of on-campus practice base, students, schools and campuses can be mobilized to cooperate, so as to form the linkage of Internet innovation and entrepreneurship studio, Internet innovation and entrepreneurship center and Internet innovation and entrepreneurship park. Among them, the Internet studio is based on students' innovative undertaking professional and voluntary combination form, Internet business incubator innovation to some extent, is the college of business incubators, as some have development prospects and development potential of the Internet provide funds to foster innovative undertaking and entrepreneurial guidance and training of adult education in practice Internet creative thinking of students.

\subsubsection{Promote the Construction of "E-Innovation+" Platform}

In the construction of off-campus practice base, "e+" platform is dedicated to the growth of adult education students entrepreneurship in China a platform, it integrating education resources, project resources, and the third party platform, to provide Internet innovation in colleges and universities entrepreneurship courses and training services, through the education for adult students to build real business environment without risk and low investment, Combine the theory and practice of Internet innovation and entrepreneurship of adult education students. "Gen e+" platform for adult education students to provide a true entrepreneur in the process, through the study of the supervision of trading in a way that the adult education students entrepreneurial data tracking, lets the stu- 
dent in the entrepreneurial process perfect entrepreneurial thinking and implementation between school and enterprise mutual benefit, mutual win-win situation, use of open education and benefit, the resources distribution of organic, Forming the positive growth of common demand points. Colleges and universities should establish relations of cooperation, with "create e+" together to cultivate students' creative thinking, through the school-platform—the third party cooperation method, based on regional and local characteristics, set up a ecosystem benign Internet innovation and promote each other, to create an ecological chain for training Internet innovation and entrepreneurship thinking. In the early stage, small projects with low difficulty, low investment and fast profits can be used as "entrepreneurial test water". In Alibaba, for example, its Taobao and Tmall network has achieved the possibility of low threshold to open a shop, can undertake business of actual combat as a platform, the establishment and the local government "start-up" rural "Taobao" creative entrepreneurial practice policy corresponds to the Internet, to the establishment and development of practice guidance thinking [10].

\subsubsection{Clarify Cooperation Responsibilities and Optimize Entrepreneurial Cooperation Management Mechanism}

Lack of organizational guarantee is an important difficulty in school-enterprise cooperation at present. The scope of school-enterprise cooperation is wide, involving a large number of subjects, and the management and decision-making affairs are complicated. Therefore, it is necessary to define the responsible units, manage the school-enterprise cooperation affairs uniformly, and give play to the management functions of planning, organization, decision-making, control and so on. Special agencies should be set up to promote cooperation between universities and enterprises. The integrated innovation and coordinated development of government, industry and education is the demand of The Times. Some developed countries have accumulated advanced experience in this field, which is worth learning from in China. The Ministry of Education, the State Administration for Industry and Commerce, the State Administration of Taxation and other relevant departments should formulate detailed plans to clarify the purpose, principles, standards and implementation measures of the measure. Relevant local units should formulate and submit workable implementation plans and clear schedules in light of local realities, so as to effectively promote school-enterprise cooperation in their respective regions to play a positive role in the training of entrepreneurial talents.

\subsubsection{Promote Symbiosis and Win-Win Results and Improve the Driving Mechanism of School-Enterprise Cooperation}

Promote both sides of the school and enterprise to actively participate in the school-enterprise cooperation, and fundamentally ensure the effective participation of both sides. We will establish an evaluation system for school-enterprise entrepreneurial cooperation, explore the modes and approaches of school-enterprise entrepreneurial cooperation, and encourage school-enterprise entrepreneurial 
cooperation, symbiosis and win-win results. Give full play to the incentive function of tax preference and honor and award to enhance the internal motivation of enterprises to actively seek cooperation between universities and colleges. The tax bureau and the industrial and commercial bureau should cooperate with the enterprise administration bureau, the industry federation and other relevant units to give preferential tax treatment to the enterprises that actively participate in the school-enterprise cooperation and have excellent performance in promoting the entrepreneurial practice of adult college students.

\subsection{Cultivate Students' Environmental Cognition Ability}

\subsubsection{Cultivate Rational Cognition of the Internet and Market Environment}

The cognition of the Internet and the market environment has a crucial influence on the cultivation of students' innovative and entrepreneurial thinking. Only by grasping the development trends of the Internet and the market trends can real entrepreneurship be realized. Adult colleges and universities should pay attention to guiding students to recognize the development status of the Internet, understand the entrepreneurial opportunities existing in the Internet, and clarify the risks existing in Internet entrepreneurship. The cultivation of innovative and entrepreneurial thinking on the Internet is not done behind closed doors. Schools and teachers should establish a relaxed and harmonious educational environment, pay attention to personalized development, and mobilize students' thirst for knowledge and entrepreneurial desire. The understanding of the Internet development trend and market environment should go out of the classroom. Only by investigating the market demand can we develop innovative and entrepreneurial thinking. In the heyday of the development of the Internet today, the market demand gradually from the mass to personalized. Only through the analysis of specific target consumer groups, can we accurately grasp the market demand, target innovation and entrepreneurship opportunities, and finally, under the guidance of professional ability, realize the establishment of management ability and comprehensive innovation thinking mode, and improve the success rate of innovation and entrepreneurship activities by using scientific overall planning method and reasonable allocation of resources.

\subsubsection{Strengthen the Education of Rational Entrepreneurial Thinking}

On the premise of encouraging students to treat entrepreneurship rationally, teachers in adult colleges and universities should help students analyze the Internet innovation and entrepreneurship environment by using successful cases of e-commerce and the common connection between each case. To improve students' ability of Internet and market, not only needs strong theoretical support, but also cultivates students' strong psychological qualities of extroversion and indomitable courage. Therefore, we must strengthen training to students for Internet innovation entrepreneurship theory, especially the "marketing" and "network marketing" infiltration of the two types of courses, only pay attention to 
management and marketing theory, can be combined with practice to cultivate the students' creative thinking, and the Internet to promote students in mediator has good self-esteem and self-motivation process which will guide practice with theory. Colleges and universities can integrate discipline competition, research learning, research experiments, academic theoretical discussion, training bases, entrepreneurial training, learning results, entrepreneurial design and other ways, and use group cooperation mechanism to extend the success point of innovation and entrepreneurship.

\section{Conclusion}

China is in a period of social transformation. The new business forms in the Internet era provide new opportunities for the cultivation of innovation and entrepreneurship ability of adult college students in China, and there are many successful cases of innovation and entrepreneurship that can be used for reference. Colleges and universities of adult education should actively meet the challenges of the new era, reform its own talent training objectives and talent training mode, establish students' cognitive ability system based on the construction of training base, constantly expand entrepreneurial thinking, and complete the work requirements of adult college students' innovation and entrepreneurship education in the new era.

\section{Conflicts of Interest}

The author declares no conflicts of interest.

\section{References}

[1] Cao, Z.C. and Hu, Z. (2014) Research on the Entrepreneurship Education and Service System to Improve the Entrepreneurship Ability of College Students. Continue Education Research, 31, 95-97.

[2] Wu, L.R. (2015) Reflections on the Cultivation of Innovative Talents in Colleges and Universities in the Internet Era. China Adult Education, 24, 49-51.

[3] Ni, C.H. (2015) The Function Orientation and Practice of "Internet+" in College Students' Entrepreneurship and Employment Education. Continue Education Research, 32, 20-22.

[4] Xu, S.M., Wen, Y. and Qi, W.J. (2015) College Students' Innovation and Entrepreneurship in the New Normal. Journal of Chinese Youth Social Science, 5, 61-64.

[5] Wang, Y.M. and Ye, A. (2015) From Maker Space to Crowd Maker Space: Functional Model and Service Path Based on Innovation 2.0. e-Education Research, 36, 5-12.

[6] Han, Y.J. (2012) Innovation of Management Operation Mechanism of Entrepreneurship Education in Universities from the Perspective of Comparative Studies. China Adult Education, 15, 12-15.

[7] Luo, X.L. (2012) Overview of the Research Status of Adult Education Theory in Japan. Adult Education, 7, 119-120.

[8] (2014) Global Entrepreneurship Monitor. Global Report. https://www.researchgate.net/publication/264953640_Global_Entrepreneurship_M 
onitor_2013_Global_Report

[9] Page West III, G., Gatewood, E.J. and Schaver, K.G. (2009) Handbook of University-Wide Entrepreneurship Education. Edward Elgar, USA.

https://doi.org/10.4337/9781848449480

[10] Busenitz, L.W., Page West III, G., Shepherd, D., Nelson, T., Chandler, G.N. and Zacharakis, A. (2003) Entrepreneurship Research in Emergence: Past Trends and Future Directions. Journal of Management, 29, 285-308.

https://doi.org/10.1016/S0149-2063(03)00013-8 